\title{
Validation of two age dependent D-dimer cut-off values for exclusion of deep vein thrombosis in suspected elderly patients in primary care: retrospective, cross sectional, diagnostic analysis
}

\author{
(c) $\frac{(1)(8)}{\mathrm{gy}}$ MPEN ACCESS
}

\author{
Henrike J Schouten resident in geriatrics ${ }^{12}, \mathrm{H} \mathrm{L}$ (Dineke) Koek geriatrician and clinical \\ epidemiologist $^{2}$, Ruud Oudega general practitioner ${ }^{1}$, Geert-Jan Geersing general practitioner ${ }^{1}$, \\ Kristel J M Janssen clinical epidemiologist ${ }^{1}$, Johannes J M van Delden professor of medical ethics ${ }^{1}$, \\ Karel G M Moons professor of clinical epidemiology ${ }^{1}$
}

${ }^{1}$ Julius Centre for Health Sciences and Primary Care, University Medical Centre Utrecht, PO Box 85500, 3508 GA Utrecht, Netherlands; ${ }^{2}$ Department of Geriatrics, University Medical Centre Utrecht

\begin{abstract}
Objective To determine whether the use of age adapted D-dimer cut-off values can be translated to primary care patients who are suspected of deep vein thrombosis.

Design Retrospective, cross sectional diagnostic study.

Setting 110 primary care doctors affiliated with three hospitals in the Netherlands.

Participants 1374 consecutive patients (936 (68.1\%) aged $>50$ years) with clinically suspected deep vein thrombosis.

Main outcome measures Proportion of patients with D-dimer values below two proposed age adapted cut-off levels (age in years $\times 10 \mu \mathrm{g} / \mathrm{L}$ in patients aged $>50$ years, or $750 \mu \mathrm{g} / \mathrm{L}$ in patients aged $\geq 60$ years), in whom deep vein thrombosis could be excluded; and the number of false negative results.

Results Using the Wells score, 647 patients had an unlikely clinical probability of deep vein thrombosis. In these patients (at all ages), deep vein thrombosis could be excluded in 309 (47.8\%) using the age dependent cut-off value compared with $272(42.0 \%)$ using the conventional cut-off value of $500 \mu \mathrm{g} / \mathrm{L}$ (increase $5.7 \%, 95 \%$ confidence interval $4.1 \%$ to $7.8 \%$ ). This exclusion rate resulted in $0.5 \%$ and $0.3 \%$ false negative cases, respectively (increase $0.2 \%, 0.004 \%$ to $8.6 \%$ ). The increase in exclusion rate by using the age dependent cut-off value was highest in the oldest patients. In patients older than 80 years, deep vein thrombosis could be safely excluded in $22(35.5 \%)$ patients using the age dependent cut-off value compared with $13(21.0 \%)$ using the
\end{abstract}

conventional cut-off value (increase $14.5 \%, 6.8 \%$ to $25.8 \%$ ). Compared with the age dependent cut-off value, the cut-off value of $750 \mu \mathrm{g} / \mathrm{L}$ had a similar exclusion rate (307 (47.4\%) patients) and false negative rate (0.3\%).

Conclusions Combined with a low clinical probability of deep vein thrombosis, use of the age dependent D-dimer cut-off value for patients older than 50 years or the cut-off value of $750 \mu \mathrm{g} / \mathrm{L}$ for patients aged 60 years and older resulted in a considerable increase in the proportion of patients in primary care in whom deep vein thrombosis could be safely excluded, compared with the conventional cut-off value of $500 \mu \mathrm{g} / \mathrm{L}$.

\section{Introduction}

Venous thromboembolism (pulmonary embolism and deep vein thrombosis) is a common disease in elderly people. In fact, the annual incidence of venous thromboembolism rises sharply with age, from an insignificant rate in children (less than five cases per 100000 people) to $450-900$ cases per 100000 people in those older than 80 years. ${ }^{12}$ Short term mortality of venous thromboembolism also increases with age, and can occur in more than $15 \%$ of elderly patients. ${ }^{13}$ Hence, especially in this age group, accurate and timely diagnosis of venous thromboembolism can be lifesaving. ${ }^{4}$ However, comorbidity often camouflages typical signs and symptoms of venous thromboembolism, and the diagnosis of deep vein thrombosis and pulmonary embolism is difficult and is often missed in elderly populations. ${ }^{4}$ 
Accurate exclusion of venous thromboembolism can be improved by the additional use of tests to measure the concentration of D-dimer (a degradation product of fibrin). Negative test results are commonly used to rule out patients with suspected venous thromboembolism and a low clinical probability. ${ }^{5}$ However, D-dimer concentration increases with age and its specificity for venous thromboembolism decreases in elderly patients. ${ }^{78}$ This effect leads to more false positive test results in elderly people (that is, detection of a lower proportion of these patients in whom venous thromboembolism can be excluded). As a result, many elderly patients could be referred to hospital unnecessarily for additional testing. ${ }^{9-11}$ Many physicians would prefer to rule out venous thromboembolism (especially in frail elderly patients) without an often burdensome referral.

To improve the diagnostic strategy of suspected venous thromboembolism in elderly patients, Douma and colleagues ${ }^{10}$ recently derived and internally validated an age dependent, D-dimer cut-off value for those with clinically suspected pulmonary embolism in secondary care. The researchers defined this cut-off value as age (years) $\times 10 \mu \mathrm{g} / \mathrm{L}$ in patients older than 50 years (for example, a patient aged 73 years would have a cut-off value of $73 \times 10=730 \mu \mathrm{g} / \mathrm{L}$ ). Use of this formula doubled the proportion of patients older than 70 years in whom pulmonary embolism could be excluded, without hampering the false negative rate of such an approach..$^{10}$ In addition, Haas and colleagues proposed an alternative, fixed cut-off value of $750 \mu \mathrm{g} / \mathrm{L}$ in patients aged 60 years and older who were referred to secondary care with symptoms of deep vein thrombosis. ${ }^{12}$ This proposed cut-off value also yielded an increased proportion of patients in whom deep vein thrombosis could be correctly excluded.

The age dependent value and fixed value can both help safely exclude venous thromboembolism in a large proportion of frail elderly patients without the need for burdensome referrals for further diagnostic work-up. However, the age dependent cut-off value was not validated for use in patients suspected of deep vein thrombosis. Since deep vein thrombosis and pulmonary embolism can be seen as expressions of the same disease,${ }^{13}$ we hypothesised that use of the age dependent cut-off value could be extrapolated to patients with suspected deep vein thrombosis. Furthermore, both the age dependent value and the fixed value were not validated in primary care. Before implementing these different cut-off values for patients with suspected deep vein thrombosis, a formal validation study would be needed..$^{14}$ Therefore, we aimed to compare the exclusion rate and false negative rate of both proposed cut-off values with those of the conventional cut-off value of $500 \mu \mathrm{g} / \mathrm{L}$ for the exclusion of deep vein thrombosis in a large cohort of patients with clinically suspected deep vein thrombosis in primary care.

\section{Methods}

\section{Patients}

We performed a retrospective analysis of data from two originally prospective, diagnostic accuracy studies that included 2086 primary care patients suspected of deep vein thrombosis. The first study was a derivation study for a new diagnostic rule to determine the presence or absence of deep vein thrombosis in primary care patients $(n=1295) .{ }^{16}$ On behalf of validation of the newly derived rule, researchers extended the study within the same setting and added 791 patients to the initial cohort ${ }^{9} 17$ (so-called temporal validation). ${ }^{18} 19$ The characteristics of these studies have been published previously. ${ }^{9}{ }^{16-17}$
In short, the studies were conducted among 110 primary care physicians affiliated with three hospitals in the Netherlands, between 1 January 2002 and 1 January 2006. The three adhering hospitals participated in a diagnostic programme in which the primary care physicians used diagnostic facilities of the hospital without referring the patient to a hospital specialist. All consecutive adults with a clinical suspicion of deep vein thrombosis were eligible for inclusion. Suspicion of deep vein thrombosis was based on swelling, redness, or pain of the lower extremities. The study excluded patients if symptoms and signs lasted for more than 30 days and if there was a suspicion of pulmonary embolism. The study also excluded patients receiving anticoagulant treatment at presentation or who were unwilling to participate in the studies. Written informed consent was obtained from patients. The studies were approved by the local ethics review boards of the University Medical Center Utrecht, the Netherlands.

Each patient was assessed for the clinical probability score according to Wells, ${ }^{21}$ and measured for plasma D-dimer (VIDAS (Biomerieux) or Tinaquant (Roche) assays). On the same day, all patients underwent reference testing by repeated compression ultrasonography of the symptomatic leg, performed with a real time, B mode, linear array sonographic scanner at 5.0-7.5 MHz (system V GE/Sonotion). ${ }^{22}$ The entire proximal deep vein system was explored for compressibility. In patients with a normal ultrasonography, the test was repeated at day seven. Deep vein thrombosis was established if at least one of the deep veins in the legs was not completely compressible at one of the two compression ultrasonography examinations, or excluded after two negative examinations (that is, revealing completely compressible veins of the legs). The performers and interpreters of the examinations (board certified radiologists) were blinded to information on the patient's history, physical examination, and D-dimer test results.

\section{Data analysis}

For the current analysis, we included only participants for whom $\mathrm{D}$-dimer test results were available $(\mathrm{n}=1374)$. We calculated the clinical probability of deep vein thrombosis for all patients using the Wells clinical prediction rule. Patients were classified according to the dichotomised Wells score as "likely" $(\geq 2)$ or "unlikely" $(\leq 1)$ to have deep vein thrombosis. ${ }^{21} \mathrm{We}$ dichotomised D-dimer concentrations by using the age dependent cut-off value proposed by Douma and colleagues in patients older than 50 years (age in years $\times 10 \mu \mathrm{g} / \mathrm{L}$ ) ${ }^{10}$; the fixed cut-off value of $750 \mu \mathrm{g} / \mathrm{L}$ in patients aged 60 years and older, as proposed by Haas and colleagues ${ }^{12}$; and the conventional cut-off value of $500 \mu \mathrm{g} / \mathrm{L}$ in patients of all ages. ${ }^{21}$

For patients with an unlikely clinical probability of deep vein thrombosis according to the Wells score, we calculated the proportion in whom deep vein thrombosis could be excluded (based on an unlikely clinical probability and a negative D-dimer test result using the different cut-off values). We also calculated the corresponding proportions of false negative results-that is, prevalence of deep vein thrombosis (as established by compression ultrasonography) among patients with an unlikely clinical probability and a negative test result. We calculated the number of patients needed to undergo a D-dimer assay to exclude deep vein thrombosis in one patient (that is, the number of patients needed to test) by dividing 1 by the proportion of patients with a negative test result and indeed without deep vein thrombosis (that is, the proportion of true negatives). ${ }^{23}$ We did analyses with SPSS version 17.0, and calculated appropriate 95\% confidence intervals using a programmable calculator application in Microsoft Office, Excel 2003. ${ }^{24}$ 


\section{Results}

Table $1 \Downarrow$ shows the baseline characteristics of all included participants with available $D$-dimer results $(n=1374)$. Mean age was 59.3 years (standard deviation 17.4), and most participants were older than 50 years $(936 / 1374,68.1 \%)$. Prevalence of deep vein thrombosis was $19.7 \%$ (270/1374). Of 1374 participants of all ages, $647(47.1 \%)$ had an unlikely clinical probability of deep vein thrombosis (Wells score $\leq 1$; table $2 \Downarrow$ ). Using the conventional D-dimer cut-off value of $500 \mu \mathrm{g} / \mathrm{L}, 272$ of these 647 participants had negative test results $(42.0 \%, 95 \%$

confidence interval $38.2 \%$ to $46.0 \%$, number needed to test 2.4 ). Two of these 272 participants had deep vein thrombosis, a false negative proportion of $0.3 \%$ ( $0.04 \%$ to $1.1 \%)$.

Using the age dependent cut-off value (age in years $\times 10 \mu \mathrm{g} / \mathrm{L}$ for patients aged $>50$ years), we could exclude deep vein thrombosis in 309 patients $(47.8 \%$, $95 \%$ confidence interval $43.9 \%$ to $51.7 \%$; table 2 ), which was an additional 37 patients (absolute increase $5.7 \%, 4.1 \%$ to $7.8 \%$, number needed to test 2.1) compared with the convention cut-off value of $500 \mu \mathrm{g} / \mathrm{L}$. The age dependent cut-off value missed one patient more than the conventional cut-off value (three missed cases (false negative proportion $0.5 \%, 0.01 \%$ to $1.3 \%) v$ two $(0.3 \%, 0.04 \%$ to $1.1 \%)$, respectively; increase $0.2 \%(0.004 \%$ to $8.6 \%)$ ).

Using the fixed cut-off value of $750 \mu \mathrm{g} / \mathrm{L}$ in participants aged 60 years and older, we could exclude deep vein thrombosis in 307 patients $(47.4 \%, 95 \%$ confidence interval $43.5 \%$ to $51.4 \%$, number needed to test 2.1 ; table 2). Compared with the conventional cut-off value of $500 \mu \mathrm{g} / \mathrm{L}$, use of the fixed cut-off value could exclude deep vein thrombosis in an additional 35 patients $(5.4 \%, 3.8 \%$ to $7.4 \%)$. The fixed cut-off value did not miss any extra cases, and the false negative rate remained at $0.3 \%(0.04 \%$ to $1.1 \%)$.

\section{Effect of age on efficiency and safety of different $D$-dimer cut-off values}

Use of the age dependent cut-off value (at age $>50$ years) and cut-off value of $750 \mu \mathrm{g} / \mathrm{L}$ (at age $\geq 60$ years) instead of the conventional cut-off value of $500 \mu \mathrm{g} / \mathrm{L}$ (at all ages) showed an increasing efficiency (that is, a higher proportion of patients in whom deep vein thrombosis could be excluded) with increasing age, without compromising safety (that is, the false negative proportion of patients). The proportion of patients aged 70-80 years in whom deep vein thrombosis could be excluded increased from $30.6 \%$ (95\% confidence interval $22.2 \%$ to $40.1 \%$; table 2) using the conventional cut-off value to $45.0 \%(35.6 \%$ to $54.8 \%$ ) using the age dependent cut-off value and $45.9 \%$ ( $36.4 \%$ to $55.7 \%$ ) using the cut-off value of $750 \mu \mathrm{g} / \mathrm{L}$. In patients older than 80 years, these proportions were $21.0 \%(11.7 \%$ to $33.2 \%$ ), $35.5 \%$ ( $23.7 \%$ to $48.7 \%$ ), and $33.9 \%$ (22.3\% to $47.0 \%$ ), respectively.

\section{Performance of age adapted cut-off values with different $\mathrm{D}$-dimer assays}

Since the original studies used two different D-dimer assays (Tinaquant or VIDAS), ${ }^{9}{ }^{16-17}$ we did separate analyses for these two assays. We found no differences between the two assays in false negative rates for any of the studied cut-off values (table $3 \Downarrow$ ). However, irrespective of the cut-off value applied, deep vein thrombosis was ruled out more frequently in the Tinaquant assay group than in the VIDAS assay group.

\section{Discussion}

This study showed that the use of an age dependent cut-off value (age $\times 10 \mu \mathrm{g} / \mathrm{L}$ in patients aged $>50$ years) and a fixed cut-off value $(750 \mu \mathrm{g} / \mathrm{L}$ in patients aged $\geq 60$ years $)$, combined with an unlikely clinical probability of deep vein thrombosis, resulted in a considerable increase in the proportion of suspected elderly patients in primary care in whom deep vein thrombosis could be safely and correctly excluded, compared with use of the conventional cut-off value ( $500 \mu \mathrm{g} / \mathrm{L}$ at all ages). Use of these proposed D-dimer cut-off values reduced the number needed to test by compression ultrasonography. This increase in diagnostic efficiency rose with age, notably in the eldest group of elderly patients. These findings are important, since further diagnostic testing can thus be avoided in these often frail elderly patients.

\section{Strengths and limitations of the study}

This study provides an external validation of two age adapted, D-dimer cut-off values previously proposed in secondary care patients with suspected venous thromboembolism, and translates these results to a large cohort of patients in primary care with suspected deep vein thrombosis.

This study had some limitations. D-dimer values were missing in 712 of 2086 participants in the original studies, because only dichotomised $\mathrm{D}$-dimer values (high $v$ low) were displayed by the laboratories in the early inclusion phase. Therefore, the availability of the $\mathrm{D}$-dimer values was time dependent. Time can change the nature of study populations. For example, a tendency for incidence of venous thromboembolism to fall in suspected patients over time has been reported. ${ }^{2}$ Therefore, we analysed whether the absence versus presence of a D-dimer value was related to observed patient characteristics. Most baseline characteristics (11 of 14) were the same in patients with and without available D-dimer values (web appendix 1); the prevalence of deep vein thrombosis and the mean Wells score also did not differ between the two groups (deep vein thrombosis $19.7 \%$ v 20.4\%, $\mathrm{P}=0.698$; mean Well score 1.66 (standard deviation 1.97) $v 1.74$ (2.20), $\mathrm{P}=0.658)$. Therefore, we believe that the exclusion of the patients with missing D-dimer values was probably not related to patient characteristics and thus did not bias our results.

We also repeated the entire analysis with the missing D-dimer values imputed, using multiple imputation techniques (web appendix 2). This advanced strategy deals with missing values, and is generally preferred over complete case analysis. In short, we based a multiple imputation regression model on the observed D-dimer values and corresponding patient characteristics. We then used this model to estimate missing values according to the observed patient's characteristics. ${ }^{25}$ This analysis yielded the same results sustaining the inferences of the complete case analysis, which further confirmed our assumption that the study findings would not change if the missing D-dimer values had been present.

Another limitation was that we used two different laboratory techniques-VIDAS, an enzyme linked immunosorbent assay (ELISA), and Tinaquant, a latex agglutation test. Although assay dependent thresholds have been suggested previously, ${ }^{26}{ }^{27}$ we based our analysis on a conventional cut-off point of $500 \mu \mathrm{g} / \mathrm{L}$ for both assays. After stratifying for type of assay, we found no differences in safety between the two tests, irrespective of the cut-off level applied (table 3). However, deep vein thrombosis could be ruled out more frequently in patients in the Tinaquant assay group than in those in the VIDAS group. These findings accord with those of Di Miso and colleagues, ${ }^{27}$ who reported a 
higher safety at the expense of a lower efficiency when using the VIDAS test, compared with the Tinaquant test.

We also used serial compression ultrasonography as the reference test. Owing to its non-invasiveness and its accuracy running close to the gold standard, compression ultrasonography has largely replaced venography in current medical practice. However, ultrasonography has shown a missed diagnosis rate of $0.57 \%$ (pooled meta-analysis, $95 \%$ confidence interval $0.25 \%$ to $0.89 \%$ ) in patients with deep vein thrombosis. ${ }^{28}$ To lower this misclassification rate, we by design repeated the compression ultrasonography at day seven. However, the true safety of the proposed D-dimer cut-off values might be slightly lower than that based on the present analysis. Moreover, the misclassification rate is known to be lower in patients with a low clinical probability of deep vein thrombosis $(0.29 \%, 0 \%$ to $0.70 \%) .^{28}$ The current analysis, however, included only patients with an "unlikely" clinical probability. Hence, any possible bias induced by our choice of reference test would probably not change the presented conclusions of our analysis.

We also caution the interpretation of our findings in patients older than 80 years, since the number of this subgroup was rather small. Finally, although the data were originally collected in a prospective manner, this study was a retrospective analysis.

\section{Comparison with other studies}

Douma and colleagues recently derived the age dependent cut-off value in three cohorts of patients with suspected pulmonary embolism (total of 5132 participants). They found a similar increase in the proportion of patients in whom venous thromboembolism could be excluded (increases of 6.3\%, 5.1\%, and $6.2 \%$ in derivation set, and validation sets 1 and 2 , respectively), compared with the current study $(5.7 \%) .{ }^{10}$

Our results also accord with the findings of Haas and colleagues, ${ }^{12}$ who found a similar although slightly higher increase in exclusion rate in suspected patients older than 60 years in secondary care $(12.8 \%)$. This small difference in increase can probably be explained by differences in the spectrum of patients (the range of comorbidities, the clinical setting, and previous test probability) between our study and the Haas study. Variations in patient spectrum have been linked with variations in disease prevalence as well as variations in diagnostic test accuracy. ${ }^{29}{ }^{30}$ In the Haas study, the prevalence of deep vein thrombosis in their hospital setting was twice as high as that found in our study $(39.1 \% v 19.7 \%)$. This higher prevalence can emerge from a shift spectrum of patients, towards fewer patients with limited forms of deep vein thrombosis and more patients with more manifested forms. This effect in turn could have resulted in a somewhat lower exclusion rate with the traditional cut-off value of $500 \mu \mathrm{g} / \mathrm{L}$, and led to a higher increase in the exclusion rate after use of the age adapted cut-off value, compared with our study.

\section{Implications for clinicians and other researchers}

After derivation and validation in secondary care,${ }^{10}{ }^{12}$ we showed that the two proposed age adapted strategies for excluding deep vein thrombosis using D-dimer measurement, have sustained external validation in a large cohort of patients with suspected deep vein thrombosis in primary care. Before implementing these strategies in daily practice, a formal, prospective impact study would need to assess the potential benefits of using an age adapted, D-dimer cut-off value in daily patient care. ${ }^{31}{ }^{32}$
Contributors: HJS, HLK, and GJG participated in the study concept and design, analysis and interpretation of data, and drafting of the manuscript. RO acquired the data. RO and KJMJ participated in the study concept and design, analysis and interpretation of data, and critical revision of the manuscript. KGMM and JJMD participated in the study concept and design, analysis and interpretation of data, critical revision of the manuscript, and study supervision. All authors are guarantors of the work. All authors participated in the revision and final approval of the manuscript, and had full access to the data of the study.

Funding: The study received financial support from the Netherlands Organization for Scientific Research (ZonMw project numbers 17088-2502, 917-46-360, and 945-04-009). The funding source had no influence on any aspect of this study.

Competing interests: All authors have completed the Unified Competing Interest form at www.icmje.org/coi_disclosure.pdf (available on request from the corresponding author) and declare: support from the Netherlands Organization for Scientific Research; no financial relationships with any organisations that might have an interest in the submitted work in the previous three years; no other relationships or activities that could appear to have influenced the submitted work.

Ethical approval: Not required.

Data sharing: No additional data available.

1 White RH. The epidemiology of venous thromboembolism. Circulation 2003;107:23(suppl 1):I4-8.

2 Silverstein MD, Heit JA, Mohr DN, Petterson TM, O'Fallon WM, Melton LJ III. Trends in the incidence of deep vein thrombosis and pulmonary embolism: a 25 -year population-based study. Arch Intern Med 1998;158:585-93.

3 Anderson FA Jr, Wheeler HB, Goldberg RJ, Hosmer DW, Patwardhan NA, Jovanovic B, et al. A population-based perspective of the hospital incidence and case fatality rates of deep vein thrombosis and pulmonary embolism. The Worcester DVT Study. Arch Intern Med 1991;151:933-8.

4 Siccama RN, Janssen KJ, Verheijden NA, Oudega R, Bax L, van Delden JJ, et al. Systematic review: diagnostic accuracy of clinical decision rules for venous thromboembolism in elderly. Ageing Res Rev 2011;10:304-13.

5 Stein PD, Hull RD, Patel KC, Olson RE, Ghali WA, Brant R, et al. D-dimer for the exclusion of acute venous thrombosis and pulmonary embolism: a systematic review. Ann Intern Med 2004:140:589-602.

6 Geersing GJ, Janssen KJ, Oudega R, Bax L, Hoes AW, Reitsma JB, et al. Excluding venous thromboembolism using point of care D-dimer tests in outpatients: a diagnostic meta-analysis. BMJ 2009;339:b2990.

7 Harper PL, Theakston E, Ahmed J, Ockelford P. D-dimer concentration increases with age reducing the clinical value of the D-dimer assay in the elderly. Intern Med $J$ 2007;37:607-13.

8 Righini M, le Gal G, Perrier A, Bounameaux $\mathrm{H}$. The challenge of diagnosing pulmonary embolism in elderly patients: influence of age on commonly used diagnostic tests and strategies. J Am Geriatr Soc 2005;53:1039-45.

9 Toll DB, Oudega R, Vergouwe Y, Moons KG, Hoes AW. A new diagnostic rule for deep vein thrombosis: safety and efficiency in clinically relevant subgroups. Fam Pract 2008;25:3-8.

10 Douma RA, le Gal G, Sohne M, Righini M, Kamphuisen PW, Perrier A, et al. Potential of an age adjusted $D$-dimer cut-off value to improve the exclusion of pulmonary embolism in older patients: a retrospective analysis of three large cohorts. BMJ 2010;340:c1475.

11 Schutgens RE, Haas FJ, Biesma DH. Reduced efficacy of clinical probability score and D-dimer assay in elderly subjects suspected of having deep vein thrombosis. Br J Haematol 2005;129:653-7.

12 Haas FJ, Schutgens RE, Biesma DH. An age-adapted approach for the use of D-dimers in the exclusion of deep venous thrombosis. Am J Hematol 2009;84:488-91.

13 Girard P, Musset D, Parent F, Maitre S, Phlippoteau C, Simonneau G. High prevalence of detectable deep venous thrombosis in patients with acute pulmonary embolism. Chest 1999;116:903-8.

14 Altman DG, Vergouwe $\mathrm{Y}$, Royston $\mathrm{P}$, Moons KG. Prognosis and prognostic research: validating a prognostic model. BMJ 2009;338:b605.

15 Moons KG, Altman DG, Vergouwe Y, Royston P. Prognosis and prognostic research: application and impact of prognostic models in clinical practice. BMJ 2009;338:b606.

16 Oudega R, Moons KG, Hoes AW. Ruling out deep venous thrombosis in primary care. A simple diagnostic algorithm including D-dimer testing. Thromb Haemost 2005;94:200-5.

17 Toll DB, Oudega R, Bulten RJ, Hoes AW, Moons KG. Excluding deep vein thrombosis safely in primary care. J Fam Pract 2006;55:613-8.

18 Altman DG, Vergouwe $\mathrm{Y}$, Royston P, Moons KG. Prognosis and prognostic research: validating a prognostic model. BMJ 2009;338:b605.

19 Toll DB, Janssen KJ, Vergouwe Y, Moons KG. Validation, updating and impact of clinical prediction rules: a review. J Clin Epidemiol 2008;61:1085-94.

20 Oudega R, Moons KG, Hoes AW. Limited value of patient history and physical examination in diagnosing deep venous thromboembolism in primary care. Thromb Haemost Family Practice 2005;22:86-91.

21 Wells PS. Integrated strategies for the diagnosis of venous thromboembolism. $J$ Thromb Haemost 2007;5(suppl 1):41-50.

22 Fraser JD, Anderson DR. Deep venous thrombosis: recent advances and optimal investigation with US. Radiology 1999;211:9-24.

23 Righini M, Aujesky D, Roy PM, Cornuz J, de Moerloose P, Bounameaux H, et al. Clinical usefulness of $\mathrm{D}$-dimer depending on clinical probability and cutoff value in outpatients with suspected pulmonary embolism. Arch Intern Med 2004;164:2483-7. 


\section{What is already known on this topic}

Combined with clinical probability testing, tests to determine D-dimer concentrations can be used to rule out patients with suspected venous thromboembolism

With increasing age, the D-dimer concentration increases and specificity of the D-dimer test decreases, resulting in a lower proportion of elderly patients in whom venous thromboembolism can be excluded

In secondary care studies, researchers proposed two age adapted cut-off values of D-dimer for elderly patients with a low clinical probability of venous thromboembolism; use of these values identified an increased proportion of patients in whom venous thromboembolism could be safely excluded

\section{What this study adds}

Two age adapted cut-off values used for exclusion of venous thromboembolism were translated to elderly patients in primary care with suspected deep vein thrombosis.

Use of these values increased the proportion of older patients in whom deep vein thrombosis could be safely excluded; this increase was largest in patients older than 80 years

An impact study is needed before introducing the use of age adapted cut-off values in daily practice

24 Rothman KJ, Boice JD. Epidemiologic analysis with a programmable calculator. National Institutes of Health (US), 1979

25 Donders AR, van der Heijden GJ, Stijnen T, Moons KG. Review: a gentle introduction to imputation of missing values. J Clin Epidemiol 2006;59:1087-91.

26 Oudega R, Toll DB, Bulten RJ, Hoes AW, Moons KG. Different cut-off values for two D-dimer assays to exclude deep venous thrombosis in primary care. Thromb Haemost 2006;95:744-6.

27 Di Nisio MF, Squizzato AF, Rutjes AW, Buller HR, Zwinderman AH, Bossuyt PM. Diagnostic accuracy of $D$-dimer test for exclusion of venous thromboembolism: a systematic review. J Thromb Haemost 2007;5:296-304.

28 Johnson SA, Stevens SM, Woller SC, Lake E, Donadini MF, Cheng JF, et al. Risk of deep vein thrombosis following a single negative whole-leg compression ultrasonography: a systematic review and meta-analysis. JAMA 2010;303:454-5.

29 Hlatky MA, Pryor DB, Harrell FE Jr, Califf RM, Mark DB, Rosati RA. Factors affecting sensitivity and specificity of exercise electrocardiography. Multivariable analysis. $A m$ Med 1984;77:64-71
30 Moons KG, van Es GA, Deckers JW, Habbema JD, Grobbee DE. Limitations of sensitivity, specificity, likelihood ratio, and Bayes' theorem in assessing diagnostic probabilities: a clinical example. Epidemiology 1997;8:12-7.

31 Reilly BM, Evans AT. Translating clinical research into clinical practice: impact of using prediction rules to make decisions. Ann Intern Med 2006;144:201-9.

32 Moons KG, Altman DG, Vergouwe $Y$, Royston P. Prognosis and prognostic research: application and impact of prognostic models in clinical practice. BMJ 2009;338:b606.

\section{Accepted: 22 March 2012}

\section{Cite this as: BMJ 2012:344:e2985}

This is an open-access article distributed under the terms of the Creative Commons Attribution Non-commercial License, which permits use, distribution, and reproduction in any medium, provided the original work is properly cited, the use is non commercial and is otherwise in compliance with the license. See: http://creativecommons.org/licenses/by$\mathrm{nc} / 2.0 /$ and http://creativecommons.org/licenses/by-nc/2.0/legalcode. 


\section{Tables}

Table 1| Baseline characteristics of study patients with clinically suspected deep vein thrombosis. Data are no (\%) of patients unless specified otherwise

\begin{tabular}{lc} 
& No of patients (N=1374) \\
\hline Age (years) & $59.3(17.4)$ \\
\hline Female & $863(62.8)$ \\
\hline Active malignancy & $61(4.4)$ \\
\hline Paresis & $194(14.1)$ \\
\hline Recent surgery or bedridden & $168(12.2)$ \\
\hline Localised tenderness in deep vein system & $966(70.3)$ \\
\hline Entire leg swollen & $596(43.4)$ \\
\hline Calf distension $\geq 3 \mathrm{~cm}$ & $551(40.1)$ \\
\hline Pitting oedema & $838(61.0)$ \\
\hline Vein distension & $254(18.5)$ \\
\hline Alternative diagnosis present & $672(48.9)$ \\
\hline History of deep vein thrombosis & $284(20.7)$ \\
\hline Wells score & $1.66(2.0)$ \\
\hline Suspected deep vein thrombosis & $270(19.7)$ \\
\hline
\end{tabular}

*Data are mean (standard deviation). 
Table 2/ Proportion of patients with unlikely probability of deep vein thrombosis (Wells score $\leq 1$ ) in whom deep vein thrombosis could be excluded, by age group. Data are no $(\%, 95 \% \mathrm{Cl})$ of patients, unless stated otherwise

\begin{tabular}{|c|c|c|c|c|c|}
\hline & \multicolumn{5}{|c|}{ Age group (years) } \\
\hline & All ages & $50-60$ & $60-70$ & $70-80$ & $>80$ \\
\hline Median age (years) & 57 & 55 & 66 & 74 & 85 \\
\hline No (\%) of patients & $647(100)$ & $126(19.5)$ & $107(16.5)$ & $111(17.2)$ & $62(9.6)$ \\
\hline \multicolumn{6}{|c|}{ Conventional cut-off value $(500 \mu \mathrm{g} / \mathrm{L})$} \\
\hline Patients below value & $272(42.0,38.2$ to 46.0$)$ & $59(46.8,37.9$ to 55.9$)$ & $35(32.7,24.0$ to 42.5$)$ & $34(30.6,22.2$ to 40.1$)$ & $13(21.011 .7$ to 33.2$)$ \\
\hline $\begin{array}{l}\text { Patients with false negative } \\
\text { result }\end{array}$ & $2(0.3,0.04$ to 1.1$)$ & 0 & $1(0.9,0.02$ to 5.1$)$ & 0 & 0 \\
\hline $\begin{array}{l}\text { Number of patients needed to } \\
\text { test }\end{array}$ & 2.4 & 2.1 & 3.1 & 3.3 & 4.8 \\
\hline \multicolumn{6}{|l|}{ Age dependent cut-off value* } \\
\hline Patients below value & $309(47.8,43.9$ to 51.7$)$ & $64(50.8,41.7$ to 59.8$)$ & $42(39.3,30.0$ to 49.2$)$ & $50(45.0,35.6$ to 54.8$)$ & $22(35.5,23.7$ to 48.7$)$ \\
\hline $\begin{array}{l}\text { Patients with false negative } \\
\text { result }\end{array}$ & $3(0.5,0.01$ to 1.3$)$ & $1(0.8,0.02$ to 4.3$)$ & $1(0.9,0.02$ to 5.1$)$ & 0 & 0 \\
\hline $\begin{array}{l}\text { Number of patients needed to } \\
\text { test }\end{array}$ & 2.1 & 2.0 & 2.6 & 2.2 & 2.8 \\
\hline \multicolumn{6}{|l|}{ Cut-off value $(750 \mu \mathrm{g} / \mathrm{L}) \dagger$} \\
\hline Patients below value & $307(47.4,43.5$ to 51.4$)$ & $59(46.8,37.9$ to 55.9$)$ & $45(42.1,32.6$ to 52.0$)$ & $51(45.9,36.4$ to 55.7$)$ & $21(33.9,22.3$ to 47.0$)$ \\
\hline $\begin{array}{l}\text { Patients with false negative } \\
\text { result }\end{array}$ & $2(0.3,0.04$ to 1.1$)$ & 0 & $1(0.9,0.02$ to 5.1$)$ & 0 & 0 \\
\hline $\begin{array}{l}\text { Number of patients needed to } \\
\text { test }\end{array}$ & 2.1 & 2.1 & 2.4 & 2.2 & 3.0 \\
\hline \multicolumn{6}{|c|}{ Absolute increase in efficiency $(\%(95 \% \mathrm{Cl}))$} \\
\hline $\begin{array}{l}\text { Using age dependent cut-off } \\
\text { valueł }\end{array}$ & $5.7(4.1$ to 7.8$)$ & $3.9(1.3$ to 9.0$)$ & $6.5(2.7$ to 13.0$)$ & 14.4 (8.5 to 22.3 ) & 14.5 (6.8 to 25.8$)$ \\
\hline Using cut-off value $(750 \mu \mathrm{g} / \mathrm{L}) \S$ & $5.4(3.8$ to 7.4$)$ & Not applicable & 9.3 (4.6 to 16.5$)$ & $15.3(9.2$ to 23.4$)$ & 12.9 (5.7 to 23.9$)$ \\
\hline
\end{tabular}

*Age (years) $\times 10 \mu \mathrm{g} / \mathrm{L}$ for patients older than 50 years; conventional cut-off value $500 \mu \mathrm{g} / \mathrm{L}$ for younger patients.

tCut-off value $750 \mu \mathrm{g} / \mathrm{L}$ for patients aged 60 years and older; conventional cut-off value $500 \mu \mathrm{g} / \mathrm{L}$ for younger patients.

$\ddagger$ Calculated as percentage of patients in whom deep vein thrombosis can be excluded by use of age dependent cut-off value minus percentage of patients in whom deep vein thrombosis can be excluded by use of conventional cut-off value.

$\S$ Calculated as percentage of patients in whom deep vein thrombosis can be excluded by use of cut-off value $750 \mu \mathrm{g} / \mathrm{L}$ minus percentage of patients in whom deep vein thrombosis can be excluded by use of conventional cut-off value. 
Table 3| Proportion of patients with unlikely probability of deep vein thrombosis (Wells score $\leq 1$ ) in whom deep vein thrombosis could be excluded, by D-dimer assay used. Data are no $(\%, 95 \% \mathrm{Cl})$ of patients, unless stated otherwise

\begin{tabular}{|c|c|c|c|}
\hline & VIDAS test $(n=323)$ & Tinaquant $(n=324)$ & $\mathbf{P}$ \\
\hline Median age (years) & 60 & 54 & $<0.001$ \\
\hline \multicolumn{4}{|l|}{ Conventional cut-off value $(500 \mu \mathrm{g} / \mathrm{L})$} \\
\hline Below value & $106(32.8,27.7$ to 38.2$)$ & $166(51.2,45.6$ to 56.8$)$ & $<0.001$ \\
\hline With false negative result & $1(0.3,0.01$ to 1.7$)$ & $1(0.3,0.01$ to 1.7$)$ & 0.971 \\
\hline \multicolumn{4}{|l|}{ Age dependent cut-off value* } \\
\hline Below value & $128(39.6,34.2$ to 45.2$)$ & $181(55.9,50.3$ to 61.3$)$ & $<0.001$ \\
\hline With false negative result & $2(0.6,0.01$ to 2.2$)$ & $1(0.3,0.01$ to 1.7$)$ & 0.527 \\
\hline \multicolumn{4}{|l|}{ Cut-off value $(750 \mu \mathrm{g} / \mathrm{L}) \dagger$} \\
\hline Below value & $128(39.6,34.2$ to 45.2$)$ & $179(55.2,49.7$ to 60.7$)$ & $<0.001$ \\
\hline With false negative result & $1(0.3,0.01$ to 1.7$)$ & $1(0.3,0.01$ to 1.7$)$ & 0.971 \\
\hline \multicolumn{4}{|c|}{ Absolute increase in efficiency $(\%(95 \% \mathrm{Cl}))$} \\
\hline Using age dependent cut-off valueł & $6.8(4.3$ to 10.1$)$ & 4.6 (2.6 to 7.5$)$ & Not significant \\
\hline Using cut-off value $(750 \mu \mathrm{g} / \mathrm{L}) \S$ & $6.8(4.3$ to 10.1$)$ & $4.0(2.1$ to 6.8$)$ & Not significant \\
\hline
\end{tabular}

$P$ values calculated by Pearson's $x^{2}$ two sided tests.

*Age (years) $\times 10 \mu \mathrm{g} / \mathrm{L}$ for patients older than 50 years; conventional cut-off value $500 \mu \mathrm{g} / \mathrm{L}$ for younger patients.

†Cut-off value $750 \mu \mathrm{g} / \mathrm{L}$ for patients aged 60 years and older; conventional cut-off value $500 \mu \mathrm{g} / \mathrm{L}$ for younger patients.

$\ddagger$ Calculated as percentage of patients in whom deep vein thrombosis can be excluded by use of age dependent cut-off value minus percentage of patients in whom deep vein thrombosis can be excluded by use of conventional cut-off value.

$\S$ Calculated as percentage of patients in whom deep vein thrombosis can be excluded by use of cut-off value $750 \mu \mathrm{g} / \mathrm{L}$ minus percentage of patients in whom deep vein thrombosis can be excluded by use of conventional cut-off value. 